\title{
VI.-Account of an Expedition to Greenland in the year 1870.
}

By Prof. A. E. NordenskiöLd,

Foreign Correspondent Geol. Soc. Lond., etc., etc., etc.

Part $V$.

(Continued from page 463.)

NOTWITHSTANDING the very inconsiderable amount of sulphur it contains, this Greenland iron has a remarkable tendency to fall to pieces by the action of the air. The weathering depends on an oxidation, probably produced by a quantity of chlorine contained in the iron, and its great porosity; nevertheless, some of the phenomena connected with the weathering still appear to me inexplicable." I shall therefore somewhat more fully detail the observations and experiments made towards explaining this very disagreeable circumstance.

The Ovifak meteoric iron does not fall to pieces at the place where it was found, though sometimes washed by the sea, sometimes left bare; but on the shore it was preserved at the temperature of the sea, which varies but little during the whole year.

Even during the passage, when the masses lay packed in wooden ehests in the hold, and were exposed to a very moist atmosphere and at a temperature but little above freezing-point, the unbroken stones did not suffer perceptibly; whereas almost all the fragments packed in the same manner split into pieces, more particularly those which I had preserved in the heated cabin.

From some of the pieces of iron sea-green drops oozed out, which afterwards became reddish brown by the action of the atmosphere. They contained protochloride of iron with traces of sulphate.

One of the larger pieces, which, after our return home, was placed in a room of ordinary temperature, soon began to crack on its surface, and ultimately, when unpacked two months later in Stockholm, crumbled to a reddish brown powder, consisting partly of a fine rust powder, partly of angular bits of iron, rusty on the surface, and varying in magnitude from the size of a pea to that of a hemp-seed. An entirely unchanged, and therefore, on a fresh surface of fracture still metallic, portion of Stone 4, began at one corner to rust, swell and crumble, while the remainder of the iron remained unaltered. The rust spread itself like a fungous growth over the rest of the piece, and extended itself to the interior, which thereupon swelled and crumbled like an efflorescent salt. During this time the weight of the piece of iron increased.

Weight of a fragment of iron when packed ................ 29.935 gr.

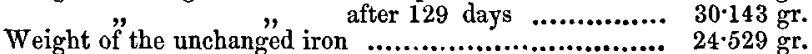

so that $5.406 \mathrm{gr}$. had weathered away to a rusty-brown powder and during this time had increased in weight $0.208 \mathrm{gr}$. or 3.8 per cent.

In a hermetically sealed glass tube the iron was completely unchanged.

In a glass tube, that had been hermetically sealed, but in which a firie crack had taken place in cooling, the iron continues to crumble

In a eudiometer over mercury, the iron in a few days absorbed a 
considerable amount of oxygen, in consequence of which the mercury rises in the tube.

In alcohol, the iron does not crumble. In water, it rusts, but does not appear to fall to pieces.

In air dried by sulphuric acid the crumbling process takes place slowly.

Varnishing does not fully protect these pieces of iron from weathering, not even if immersed in warm copal-varnish. I thought at first that the cracking was the result of the contracting and shrinking of the mass, but this is not the case. On the contrary, the cracking is caused by dilatation. With what force this operates may be judged from the fact, that a piece of iron, on which chisel and saw are without effect, is broken or bent by the decomposition of the mass. In general, cracks first appear at right angles to the surface of the stone; these diverge as from a centre, and at a depth of a few lines below the surface of the stone meet a crack that runs parallel with the surface, which, by the swelling of the overlying crust, is soon formed into a little dome, sometimes an inch in height. In the mean time the overlying crust is raised, doubled up and broken in a manner which bears a striking likeness to the doubling of the stratified rocks by the so-called eruptive forces, - that is, if one supposes that the cracks, instead of being empty, are filled with detritus, which gradually hardens to an "eruptive" rock.

When fragments of the largest stone weighing $134 \mathrm{gr}$. were heated to redness, they parted with nearly two litres of gas, or about 100 times the volume of the iron, as also a considerable amount of water, which, like the gas, had a bituminous smell. The gas was clearly no primary constituent, but formed partly by the decomposition of organic matter in the meteorite, partly by the reducing operation of compounds containing carbon on the oxide of iron in the meteorite, which was found to be completely reduced at the termination of the experiment. On the iron being dissolved in chloride of mercury, only a trifling quantity of gas was emitted, probably coming from the pores in the iron. In hydrochloric and nitric acid the meteoric iron is dissolved, leaving in some cases a residue containing much carbon, in others very little residue at all. The gas that escapes during solution in hydrochloric acid has a most penetrating smell, probably due to some hydrocarbon. On dissolving Ovifak iron, which has been heated to redness, in air or oxygen, in acid, there often remains a flocky, voluminous, brown material soluble in warm, but hardly so in cold water, which in ammonia is very easily dissolved, forming a dark brown, almost opaque fluid. The same material is obtained from the carbon that remains after the solution of the iron in acids. It can again be precipitated by means of acids from the ammoniacal solution, though not quite completely, so that the acid solution is also brown, but of a very light tint. This material is a humus-like compound, which probably did not originally exist in the meteorite, but arises from the solution of the carboniferous iron in acids. ${ }^{1}$ This humus-like body can be broken

${ }^{1}$ A similar substance, obtained by dissolving iron containing carbon, has been 
up only with difficulty by long boiling in strong nitric acid or chlorate of potash and hydrochloric acid.

The following analyses have been made of this iron from Ovifak:-

r. Analysis of a fragment from one of the large stones, by A. E. Nordenskiöld. II. Analysis of a specimen of more compact iron, by Th. Nordström. III. Analysis of iron with conspictous Widmanstättian figures from the basalt ridge by $\mathrm{G}$. Lindström.

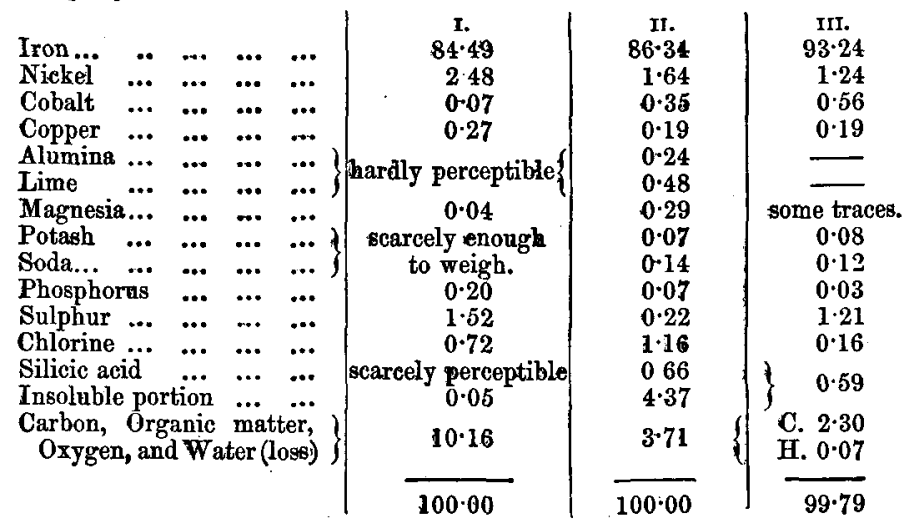

I. Contained scarcely any traces of silicic acid, alumina or lime. The iron was therefore entirely free from silicates, although large lumps of basalt were firmly rusted on to the surface of the meteorite, and one or two fragments of basalt surrounded with iron oould be observed within the iron near the surface. Even before heating to redness, r. emitted a good deal of water and gas, as much apparently as amounted to about 100 times the volume of the iron,- that is to say, considerably more than the iron examined in Analyses I. and II. This explains the large loss in $\mathrm{r}$. The specific gravity of 1 . was ascertained, from two (porous) fragments of some grammes weight, to be 6.36 and 5.86. The smaller specific gravity here arises evidently from the large quantity of carbonaceous matter that is contained in this iron. Nordström obtained the specific weight of Ir. from two experiments on small pieces $=7 \cdot 05$ and $7 \cdot 06$. Lindström found the specific gravity of IIr. at $17^{\circ} \mathrm{C}$. to be equal to $6 \cdot 24$. The iron employed in Analysis Ir. was less crystalline and more compact than that used in Analysis I. It was hard to break, and small grains could be hammered flat without disintegration. In Analyses Ir. and III. the materials examined were in external appearance precisely alike, and I

mentioned by Berzelius, in Afhandl. i Fysik, Kemi oeh Afineralogi. When iron containing carbon is dissolved in hydrochloric acid of proper strength and temperature, not only is this bumus-like matter generated, but hydro-carbons also, and (according to a statement made to me by Prof. Eggertz) even fluid hydro-carbons, the atomic composition of which is very complicated. We have here, then, a method for attempting the synthesis of organic substances from their inorganic components unemployed hitherto, as far as I am aware, in synthetic organic chemistry. Iron containing carbon was pointod out by Berzelius in 1818 (Aph. i. Fysik, Kemi, etc., vol. v. p. 534) as an inorganic material which might serve as a means for the synthetical formation of organic compounds. 
therefore consider it as probable that the material of II. also was from the basalt ridge, although it had afterwards crumbled apart.

1v. Analysis of the silicate that remained undissolved in Analysis IJ. by Dr. Th. Nordström. v. Analysis of a piece of basalt firmly rusted on to the surface of the largest meteorite, by $\mathrm{Dr}$. Th. Nordström.

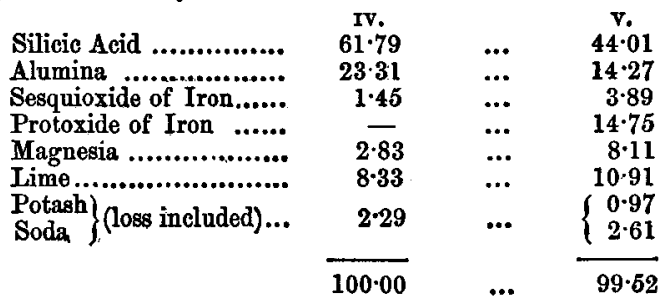

vr. and vII. Analyses of the carbonaceous matter in the iron of rr. by Nordström, 33.0479 gr., gave after first treating with chloride of copper, and afterwards with chloride of iron, 4.79 per cent. of a carbonaceous matter, containing $\mathbf{4 2 . 5 8}$ per cent. ash. An elementary analysis of this carbonaceous matter, deducting the ash, gave-

$\begin{array}{lrrr} & \text { vI. } & & \text { vIr. } \\ \text { Carbon ..................... } & \mathbf{6 3 \cdot 5 9} & \ldots . & 63 \cdot 64 \\ \text { Hydrogen............... } & \mathbf{3 \cdot 2 6} & \ldots . & 3.55 \\ \text { Oxygen (loss included).. } & \mathbf{3 3 \cdot 1 5} & \ldots & 32 \cdot 81 \\ & \mathbf{1 0 0 \cdot 0 0} & \ldots & 100 \cdot 00\end{array}$

The substance is not soluble in either alcohol, ammonia, or potash, and evidently consists of a mixture of organic matter, water and carbon.

The discovery at Ovifak is remarkable, not only as the largest discovery of meteorio iron hitherto known to have been made, but also as that which is richest in carbon, excepting the carbon powder that fell at Hessle. Add to this, the remarkable ciroumstance, partly that lenticular and discoidal pieces of native iron occur at the same place in the underlying basalt, partly that basalt pieces of considerable size, in numerous spots, form a crust on the larger meteorites, and are even sometimes met with driven through the surface into the iron. Nevertheless, in spite of this, it appears to me that there cannot be a doubt of the really meteoric origin of the large masses. Their form, their composition, their appearance, sufficiently indicate this. To explain the occurrence of meteoric iron together with basalt we must then assume:

(1) Either that the ridges FG and GH (see map ${ }^{1}$ ) are only apparently in solid connexion with the rock, but are really only fragments of one large meteorite of 20 to 40 feet in diameter, formed principally of a mass of basalt-like matter, with balls of iron disseminated through it, that has fallen at this spot. This assumption would, however, be too hazardous, and is rendered improbable by the circumstance that the basalt that surrounds the meteoric iron is perfectly similar to the exact variety of the Greenland basalt, which forms the rocks of the

$l$ Published with Part II. in the August number, p. 355. 
locality.' The greatest part of the stone mass into which the iron particles are scattered is, however, very unlike genuine basalt, and in external appearance rather resembles the meteoric stone from Tanacera Pass, in Chili. Time has not yet permitted a more accurate investigation.

Or, (2) that the whole fall of meteoric iron took place during the period when the piling up of these Greenland basalt rocks was in progress, i.e. during the latter portion of the Cretaceous and the beginning of the Tertiary periods. Some of the pieces of meteoric iron have fallen to iron-dust, and filled cracks in the basalt, where they have again hardened into the iron above described as found in the ridge FG. Of similar origin are also the particles of native iron in the basalt lying nearest the iron, which occasionally has a conglomerate-like structure.

As considerable masses of iron, of a composition probably very similar to that of meteoric iron, without a doubt occur in the interior of the earth, it may be suggested that the Ovifak iron may be of telluric origin, and that it has been, together with the plutonic rocks, thrown up during the eruptions that have given rise to the vast strata of basalt in this neighbourhood. But not only does the fully marked meteoritic form of the many iron pieces militate against this supposition, but also the circumstance that the iron in question-as the facts of its containing organic matter, its porosity etc., showhas evidently never been heated even to a temperature of a few hundred degrees.

Neither is it possible that these masses of iron can have arisen from the reduction by gases developed in connexion with basalt eruptions of a ferruginous mineral. Iron pyrites cannot be reduced by these means, while no oxide-of-iron-mineral containing nickel, and at the same time almost free from lime and silica, is known. The formation of the iron from chloride of iron, which had been erupted from the interior of the earth and since been reduced, can hardly be supposed. The explanation I have given above, that the iron is the result of an unusually rich Miocene fall of meteoric iron, seems, therefore, to me most plausible.

Öberg also was fortunate enough to meet with a piece of meteoric iron from the neighbourhood of Jakobshavn. He received the piece, which weighed $7 \frac{1}{2}$ Skålpund ( $7 \mathrm{fb}$ Avoird.), from Dr. Pfaff, of Jakobshavn. This piece, which is now preserved in the Riks Museum at Stockholm, is an oval Iump, with a somewhat rough surface, consisting principally of very hard, tough, not crumbling iron. On being sawn through, it presented the appearance of a mass of iron grain's welded together, here and there impregnated with a basalt-like black silicate. On etching, fine Widmanstättian figures are obtained. We have not had time to analyse it, and I need not therefore dwell longer on the description of it, especially if, as is greatly to be wished, ${ }^{2}$ the three larger iron blocks left at Ovifak

1 Only the basalt in some parts of the ridge FG and GH, but not the basalt from other districts of Disko and Noursoak, does contain native iron.

${ }^{2}$ As I have above mentioned, the Swedish Government sent for this purpose 
should be brought home, in which case $I$ shall be enabled to give a complete account of all the Greenland discoveries of iron, together with more analyses. I will here simply enumerate the discoveries of iron hitherto made on the western coast of Greenland.

(1). Ross and Kane's discovery of iron in Davis Strait.-According to these famous polar navigators, the Esquimaux in North Greenland make knives and instruments of iron from some large blocks situated probably somewhere to the north of Upernivik.

(2). Rink's discovery of iron at Niakornak, Jakobshavn District.In 1847 Rink found in the possession of some Greenlanders an iron ball, which they said they had found in a plain covered with boulders near the mouth of the Anorritok River. It weighed 21tb, with a specific gravity of 7.02. Analysed by Forchammer. Crumbling scarcely perceptible.

(3). Rudolph's discovery of iron at Fortune Bay.-A piece of iron weighing 11,844 gr. was found by Colonial Governor Rudolph among ballast that had been taken in at Fortune Bay. The iron crumbles much, and belongs probably to the same fall as the iron found at Ovifak.

(4). Fiskernäss.-A small piece of metallic iron was found by Rink at Fiskernäss in South Greenland. The iron was declared by Forchammer to be of meteoric origin.

And lastly :-

(5). The Pfaff-Öberg iron from Jakobshavn.

(6). The iron discovered at Ovifak.

Lastly it should be mentioned, that the old northern chronicles state, that during the time the old colonies existed in Greenland, so violent a shower of stones once happened that several churches and other buildings were destroyed.

- It is remarkable that Giesecke, in his many years of travel in Greenland, should not have met with any meteoric iron, whereas he mentions that huge balls of iron pyrites were found in the sand-beds of the basalt formation. We also met with some such balls at an elevation of a couple of hundred feet above the sea, between Ujarasusuk and Kudliset. They were as much as from 3 to 4 feet in diameter, spherical, and lay loose in the sand close to a basalt dyke. Nevertheless; they did not contain pyrites, but a mineral (not yet analysed) like magnetic pyrites of a very unusual appearance.

In our excursions round Disko Bay and the Waigat, I availed myself of such opportunities as offered themselves for astronomical determinations of localities. These have since been calculated by Mr. Edward Jäderin, and a detailed account of them will hereafter be published. Here I shall only append a table of the results of the calculations, together with a copy of a part of Rink's map of North Greenland, corrected according to these geographical determinations,

an expedition to Greenland, 1872, which succeeded in bringing home not only the three meteorites of 21,8 , and 4 tons, but also several smaller ones of from 4 to 200 kilogr. 
and a small number of angular measures. The places whose positions were astronomically determined by us are on the map marked with a cross. Spots where fossil plants were discovered are distinguished by a different mark.

Geographieal Determinations made in the Expedition of 1870, calculated by E. Jäderin.

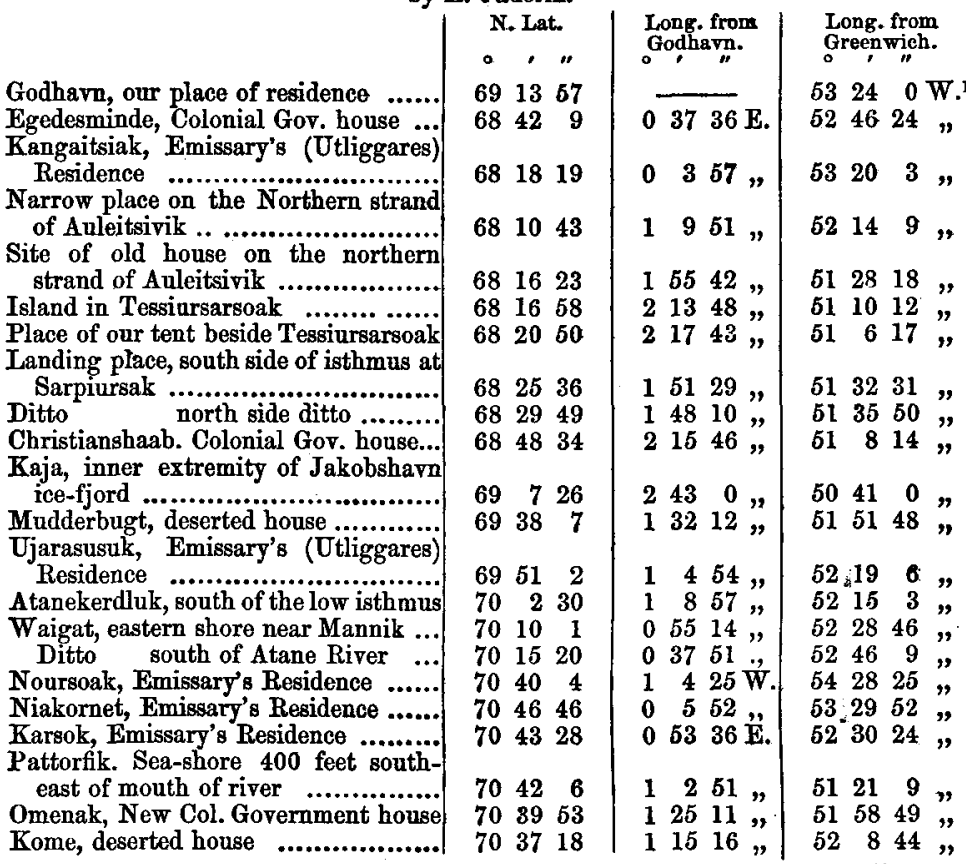

It was hardly compatible with Dr. Berggren's and Öberg's botanical and zoological interests to participate in the long, tedious, boat excursions Dr. Nordström and I intended to make round the shores of Disko Island and Noursoak peninsula, and accordingly, as above stated, after the excursion to Kaja, our little expedition divided itself into two parties on the 31st of July. The proceedings of the one party I have already related : concerning those of the other, Dr. Berggren has made the following communication :-

"It was Aug. 1, at 5 A.M.,' that we took leave of each other, Prof. Nordenskiöld and Dr. Nordström to proceed to the peninsula of Noursoak, Dr. Öberg and I to continue our zoological and botanical researches up to the mouth of the Waigat. Claushavn, which formed our principal station from the 1st to the 13th of August, offered-on account of the roominess of the Colonial Governor's house, which was placed at our disposal-a convenient place for arranging and preserving the collections made in the previous boat excursions, but which it had previously been impossible to treat with sufficient care.

1 According to Graah's determination. 
For the purpose of dredging, for which two crews were sometimes employed, new men were obtained from Claushavn, and those we had hitherto employed were dismissed home. The country round about the colony is a plain rich in flowers, surrounded by hills of only a few hundred feet high, with a fenny moor-land soil, and a small lake in the middle. This, like other lakes in the neighbourhood, was interesting both in zoological and in botanical respects, on account of three phanerogamous plants, not previously met with in Greenland, being there found. As the stay of nearly two weeks which we made here happened just when the phanerogamic flora-which, in consequence of the varied nature of the ground, is here very richly represented-is in its fullest flower, and as moreover the moss-flora, for the same reasons, is one of the richest in the gneiss-regions, and the dredgings brought in a number of marine algæe, the botanical collection made at Claushavn forms a considerable part of the whole.

"We left Claushavn in the afternoon of the 13th of August, and after three or four hours rowing, passed the ice-stream, just at that moment giving off its ice into the sea, to Jakobshavn. In consequence of the vicinity of that colony to the ice-stream; the dredging here produced an interesting collection of marine animals, as well as of algæ, among which was the Laminaria solidungula, previously only known as belonging to Spitzbergen. The ruins and dirt-beds at the old deserted site of Sermermiut were examined, and both from thence and other places a number of flint tools were collected. The country immediately around the colony consists of low rounded hills, but further inland lies a tolerably extensive plain, with marshy soil and some lakes, which is again inclosed by higher mountain ridges. This likeness to the environs of Claushavn causes the vegetation at the two places to be generally of a similar nature.

"Aug. 19. At 11 A.M. we left Jakobshavn, and steering our course northward, arrived in the evening at the mouth of Illartlek. After passing through the narrow entrance to that fjord, inclosed on either side by lofty cliffs, where there is a very strong current, we encamped at 11 P.M. beside a little calm harbour in the peninsula, which separates the two arms of the gulf.

On the 20th and 21st dredgings and botanical excursions were made into the inner part of the gulf, extending nearly up to the inland ice. It was from this point that Whymper and Brown ascended the inland ice in 1867. I occupied myself principally with examining the vegetation of the mountain tops, which do not here usually exceed 1000 feet in height. Instead of the fine weather which had hitherto favoured us, on the 21st of August it began to rain, which hindered our work, and the rain flowed down in such quantities from the mountain slopes over the spot where our tent stood, that we were obliged to leave. To get under cover we first rowed to the Greenlanders' houses at Pakitsok. Rain and contrary winds detained us in these cottages (uninhabited during the summer) till the afternoon of the 23rd of August, when we departed for Ritenbenk, where we arrived in the night between the 23rd and 24th of August.

"In contrast to the southern side of Disko Bay, the mountains on 
the northern side, about Illartlek and Arveprindsens Eiland, sometimes attain a height of 2000 feet, and frequently terminate towards the sea in perpendicular walls. In consequence of this greater height, the snow lies there longer in the summer, which gives rise to a constant moisture on the hill-slopes; and these two circumstances produce a landscape and a vegetation of a character different from those of the more southern regions. Several of the valleys on Arveprindsens Island, as well as their fresh-water lakes and surrounding mountain heights, were visited by us. From Ritenbenk we undertook (Aug. 29th, Sept. 1st) a boat excursion to Kikertak Island, in the interior of a fjord on the southern part of Noursoak peninsula. Dredgings were made in the water, here chilled by the ice-stream of Tossukatek, and excursions were undertaken along the hill-slopes of Noursoak peninsula to Majorsoeitsiak, with the view of studying the vegetation of that desolate locality, where belts of inland ice extend in the form of glaciers into the valleys, which in many parts are almost bare, covered with stone boulders, and with little lakes at the bottom.

The vessel "Rjukan," hired by the Danish Trade, had, on the 28th of August, arrived at Ritenbeuk, and, as the time for our return home was fast approaching, we sailed on the 7th of September by that vessel to Godhavn, where Nordström had already arrived. The botanical and zoological excursions, which on our former visit to this place in July had been interrupted by the preparations for boat journeys, were now resumed, while the vessel lay at Godharn to unload and reload.

"Frequent falls of snow announced the approach of winter. On the 18th September the "Rjukan" weighed anchor for Sukkertoppen (the Sugar-loaf), in South Greenland. When, on the 22nd of September, we reached that colony, the winter had already commenced, and snow a foot deep covered the ground. Though the vessel cleared by the 4th of October, we were detained, by contrary winds and the consequent failure of our repeated attempts to get out of the harbour, till the 21 st of October. Favoured during the rest of the voyage by a fair wind, which for some days on the Atlantic rose to a storm, we arrived at Kleven, in Norway, on the 11th of November, whence we started by steamboat, and arrived at Gothenburg on the 17 th of November."

\section{REVIEWS}

I.-The Physical Geology and Geography of Great Britain. By A. C. Ramsay, LL.D., F.R.S. Third Edition. 8vo., pp. 349. (London: Stanford.)

A S a true philosopher ought to subordinate everything to his love A of truth, one of his principal characteristics must ever be a tendency to change opinion with the progress of discovery, without regard to his reputation for consistency. Among the great living philosophers whose opinions have changed on many important subjects, we must include Professor Ramsay. It is true that such thanges of opinion are not calculated to inspire the outside world 